\section{Hospitalizations Related to Hepatitis C Infection in Spain: Epidemiology and Comorbidi- ties}

\author{
Ruth Gil-Prieto ${ }^{1,4^{*}}$, Stefan Walter ${ }^{2,7}$, Alba Gonzalez-Escalada ${ }^{3,4}$, \\ Jesús San Román-Montero ${ }^{5}$, Javier Castrodeza-Sanz ${ }^{6}$ and \\ Angel Gil-de-Miguel ${ }^{1,4}$
}

${ }^{1}$ Area of Preventive Medicine \& Public Health, Rey Juan Carlos University, Madrid, Spain

${ }^{2}$ Fundación de Investigación biomedical, Hospital de Getafe, Madrid, Spain

${ }^{3}$ Area of Medical Microbiology, Rey Juan Carlos University, Madrid, Spain

${ }^{4}$ Cátedra de Evaluación de Resultados en Salud, Rey Juan Carlos University, Madrid, Spain

${ }^{5}$ Area of Medicine, Rey Juan Carlos University, Madrid, Spain

${ }^{6}$ Department of Preventive Medicine and Public Health, Valladolid University, Valladolid, Spain

${ }^{7}$ Department of Epidemiology and Biostatistics, University of California, San Francisco, USA

\begin{abstract}
Background: This epidemiological survey estimates the burden of hepatitis C infection in Spain during an 11 year period (2004-2014).

Methods: Retrospective survey reviewing data of the National Surveillance System for Hospital Data, including more than $98 \%$ of Spanish hospitals. All hospitalizations related to hepatitis C infection in the Spanish general population reported during 2004 - 2014 were analyzed. Hospitalizations were selected using the $9^{\text {th }}$ International Classification of Diseases.

Results: A total of 540,802 hospitalizations were reported during the study period. The annual incidence of hospitalization was 109.16 cases per 100,000 populations. The average length of hospital stay was 9.26 (SD: 12.43) days. 36,235 deaths were reported. Hospitalization and mortality rates were significantly higher in men and
\end{abstract}

*Corresponding author: Ruth Gil-Prieto, Area of Preventive Medicine and Public Health, Rey Juan Carlos University, Madrid, Spain, Tel: + 34 914888625; Fax: +34 914888955; E-mail: Ruth.gil@urjc.es

Citation: Gil-Prieto R, Walter S, Gonzalez-Escalada A, Román-Montero JS, Castrodeza-Sanz J, et al. (2017) Hospitalizations Related to Hepatitis C Infection in Spain: Epidemiology and Comorbidities. J Gastroenterol Hepatology Res 2: 010.

Received: September 09, 2017; Accepted: October 25, 2017; Published: November 14, 2017 increased significantly with age. Although there was an important peak at 40-49 years old, the highest hospitalization and mortality rates were found in the elderly.

Conclusion: The hospitalization burden of hepatitis $C$ and its related comorbidities and complications is very high in Spain. Studies reporting the burden of hepatitis $C$ related hospitalizations and their associated comorbidity have been useful in the past and will be needed to evaluate the success of therapeutic measures. The use of effective treatments has reduced the burden of disease in Spain in the last decade.

Keywords: Epidemiology; Hepatitis-C; Hospitalizations

\section{Introduction}

Hepatitis $\mathrm{C}$ Virus (HCV) infection is an important and increasing public health problem for most countries in the world. Total global $\mathrm{HCV}$ prevalence is estimated at 2.5\% (177.5 million of HCV infected adults), ranging from $1.3 \%$ in Americas to $2.9 \%$ in Africa, with a global viraemic rate of $67 \%$ (118.9 million of HCV RNA positive cases), varying from $64.4 \%$ in Asia to $74.8 \%$ in Australasia [1].

To the date, no national study to assess the real situation of $\mathrm{HCV}$ infection has been performed in Spain, although based on the limited regional studies published, the global prevalence is estimated to be around $1.5 \%[2,3]$. HCV primary infection causes an acute hepatitis that is often clinically unnoticed and evolves in more than $80 \%$ of the cases to chronicity $[4,5]$. The chronic affectation of the hepatic parenchyma can develop inflammation in the liver and the development of cirrhosis after $20-30$ years. Up to $5 \%$ of the patients will develop a hepatocellular carcinoma. Several clinical conditions such as immunodepression or HIV coinfection favor a faster progression to these severe outcomes of hepatic disease [6]. Chronic HCV infection is the main cause of hepatic cirrhosis in Spain and responsible of 32\% of the hepatic transplants [2,3]. Liver cancer is among the leading causes of cancer deaths in many countries and most of these cases can be prevented through vaccination, antiviral treatment, safe blood transfusion and injection practices, as well as interventions to reduce excessive alcohol use [7].

HCV infection can not only affect the liver, but also other organs. It is known that up to $74 \%$ of the patients will develop at least one extrahepatic complication during the disease duration, being quite often this extrahepatic symptom the first signal for the suspicion of the $\mathrm{HCV}$ infection $[8,9]$. These extrahepatic manifestations comprise a huge variety of pathologies among which mixed cryoglobulinemia, non-Hodking lymphoma, type II diabetes and several renal, dermatologic, neurologic and thyroid disorders are the most frequent [8-10]. All of them contribute to deteriorate the HCV patient's state and increase the need of hospitalization and medical care.

The treatment of hepatitis $\mathrm{C}$ has quickly evolved in the last years. It started with interferon in monotherapy. More recently, HCV NS5B polymerase inhibitor sofosbuvir has shown to result in suppression of HCV replication and has emerged as an important component of currently recommended regimens. In 2014, the FDA approved an all oral regimen of simeprevir plus sofosbuvir for treatment-naive or 
treatment-experienced patients and the combination of ombitasvir/ paritaprevir/ritonavir and dasabuvir for the treatment of genotype 1 chronic hepatitis $\mathrm{C}$ infection in adults, including patients with compensated cirrhosis $[11,12]$. On June $28^{\text {th }} 2016$, the US Food and Drug Administration (FDA) approved sofosbuvir/velpatasvir. In HCV-infected patients with cirrhosis, sofosbuvir/velpatasvir was approved for use in combination with the drug ribavirin [13].

Despite the high prevalence of hepatitis $\mathrm{C}$ infection and the increase in associated hospitalizations, studies describing the incidence of hospitalizations related to hepatitis $\mathrm{C}$ infection and their hepatic and extrahepatic complications are scarce and refer to other countries [14-17]. The recent availability of new antiviral drugs against hepatitis $\mathrm{C}$ virus, with improved efficacy and better safety profiles, enable us to discern an important change in the current management of the disease. An evaluation of the burden of hospitalization related to hepatitis $\mathrm{C}$ infections on a country level would help to assess the current situation and sanitary impact of the infection. The objective of this study is to estimate the incidence of hospitalizations associated with hepatitis C and the most frequent comorbidities from 2004 to 2014 in Spain.

\section{Materials and Methods}

A retrospective study using the national information system for hospital data (Conjunto Mínimo Básico de Datos (CMBD)) from the Ministry of Health was performed. This system uses clinical codes from the Spanish version of the $9^{\text {th }}$ International Classification of Diseases (ICD-9-MC) and includes an estimated 98\% of admissions in public hospitals and $99.5 \%$ of the Spanish population [18-20].

All hospital discharges for hepatitis C (ICD 9 CM: (070.41: Acute hepatitis $\mathrm{C}$ with hepatic coma, 070.44: Chronic hepatitis $\mathrm{C}$ with hepatic coma, 070.51: Acute hepatitis $\mathrm{C}$ without mention of hepatic coma, 070.54: Chronic hepatitis $\mathrm{C}$ without mention of hepatic coma, 070.7: Unspecified viral hepatitis $C, 070.70$ : Unspecified viral hepatitis $\mathrm{C}$ without hepatic coma and 070.71: Unspecified viral hepatitis $\mathrm{C}$ with hepatic coma) any listed diagnosis position, among general population reported during an 11-year period (January 1, 2004 through December 31, 2014) were obtained.

For each case, information on age, sex, average length of hospitalization and comorbidity was extracted. Patients were grouped by age in 5 year intervals. Most frequent hepatic and extrahepatic complications and comorbidities were reported.

\section{Statistical methods}

The annual incidence of hospitalization admissions (per 100,000 population), Average Length Of Stay in the hospital (ALOS), mortality rate (per 100,000 population) and case-fatality rate (\%) were calculated using as denominator data on the corrected population figures obtained from population registries. The distribution by age of the population covered in this study is considered to be equal to the general population.

Differences in proportions were assessed by the Chi-square test and ANOVA and post hoc Bonferroni correction was used for multiple comparisons. Poisson regression was used to assess differences in the hospitalization rate during the study period.

In all test the significance level used was $p<0.05$. Statistical analyses were performed using the Statistical Package for Social Sciences
(IBM SPSS/PASW for windows, version 22.0; Chicago, IL, USA) and R Studio, version 3.0.3).

\section{Results}

A total of 540,802 hospital discharges related to hepatitis C infection were reported during the 11-year study period. Of those 341,946 (63\%) occurred in men and 198,824 (37\%) in women. Mean age was 56.50 (SD 16.78) years old and the average length of hospital stay was $9.26(12.43)$ days. The $16.6 \%$ of the patients were readmitted in the following month due to a cause related to hepatitis $\mathrm{C}$ infection. Distribution of age and sex did not change significantly during the study period.

Table 1 shows the hospitalization rate for hepatitis $\mathrm{C}$ during the study period. The hospitalization rate was 109.16 cases per 100,000 population (CI 95\%: 108.87-109.45), being significantly higher ( $\mathrm{p}<$ 0.001 ) in men with 139.87 cases per 100,000 population (CI 95\%: $139.40-140.34)$, than in women with 79.24 cases per 100,000 population (CI 95\%: 78.89-79.59). The trend of the hospitalization rates is increasing during the study period, but an abrupt decrease can be observed in 2011.

\begin{tabular}{|c|c|c|c|}
\hline \multirow{2}{*}{ Year } & \multicolumn{4}{|c|}{ Hospitalization rate/per 100,000 (CI 95\%) } \\
\cline { 2 - 4 } & Males & Females & Total \\
\hline 2004 & $164.87(163.13 ; 166.62)$ & $93.83(92.54 ; 95.13)$ & $128.84(127.76 ; 129.92)$ \\
\hline 2005 & $161.27(159.57 ; 162.97)$ & $93.44(92.16 ; 94.72)$ & $126.94(125.87 ; 128.00)$ \\
\hline 2006 & $154.82(153.16 ; 156.47)$ & $90.13(88.88 ; 91.38)$ & $122.10(121.07 ; 123.14)$ \\
\hline 2007 & $156.44(154.79 ; 158.10)$ & $88.72(87.49 ; 89.95)$ & $122.19(121.16 ; 123.22)$ \\
\hline 2008 & $155.18(153.55 ; 156.81)$ & $91.43(90.19 ; 92.67)$ & $122.99(121.97 ; 124.01)$ \\
\hline 2009 & $153.33(151.72 ; 154.94)$ & $90.27(89.05 ; 91.49)$ & $121.46(120.45 ; 122.46)$ \\
\hline 2010 & $150.45(148.86 ; 152.05)$ & $86.47(85.28 ; 87.67)$ & $118.08(117.09 ; 119.07)$ \\
\hline 2011 & $107.16(105.82 ; 108.50)$ & $57.51(56.53 ; 58.48)$ & $82.00(81.18 ; 82.83)$ \\
\hline 2012 & $108.40(107.05 ; 109.75)$ & $59.38(58.39 ; 60.36)$ & $83.54(82.71 ; 84.37)$ \\
\hline 2013 & $115.47(114.07 ; 116.87)$ & $62.56(61.55 ; 63.58)$ & $88.60(87.74 ; 89.46)$ \\
\hline 2014 & $116.17(114.76 ; 117.57)$ & $61.5(60.50 ; 62.51)$ & $88.37(87.51 ; 89.23)$ \\
\hline Total & $139.87(139.40 ; 140.34)$ & $79.24(78.89 ; 79.59)$ & $109.16(108.87 ; 109.45)$ \\
\hline
\end{tabular}

Table 1: Hospitalization rate (per 100,000) due to hepatitis C by sex in Spain (2004-2014).

Figure 1 shows the hospitalization rate for hepatitis $\mathrm{C}$ by age. It increases significantly with age $(\mathrm{p}<0.001)$, reaching the highest incidence of hospitalization in the elderly aged 75-79 years old with a hospitalization rate per 100,000 population of 289.92 (CI 95\%: 287.42-292.37). There is an important peak in the hospitalization rate in adults aged 35-55 years old with figures up to 193.66 (CI 95\%: 192.24-195.09) per 100,000.

Hospitalization rates were also studied by region and results are shown in figure 2. The highest rates were reported in Madrid 145.59 cases (CI 95\%: 144.68-146.50) per 100,000 and Catalonia 152.35 cases (CI 95\%: 151.49-153.21) per 100,000 and the lowest were reported in Extremadura 71.61 cases (CI 95\%: 70.09-73.14) per 100,000 and Navarra 72.74 (CI 95\%: 70.70-74.78) per 100,000.

The average length of hospital stay was significantly higher in men than in women, with 9.35 (SD: 12.89) days vs. 9.11 (SD: 11.59) days $(\mathrm{p}<0.001)$, respectively, and decreased significantly $(\mathrm{p}<0.001)$ during the study period from 9.57 (SD: 12.79) days in 2004 to 8.62 (SD: 11.7) days in 2014. 


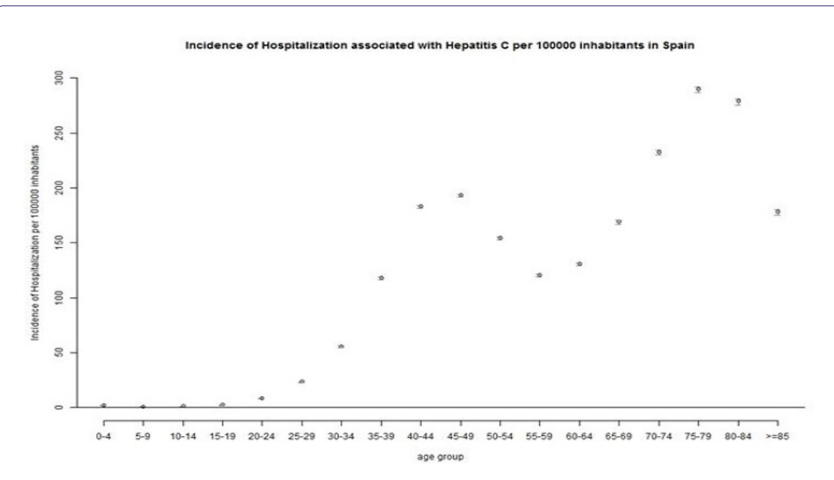

Figure 1: Hospitalization rates related to hepatitis $\mathrm{C}$ by group of age in Spain (2004-2014).

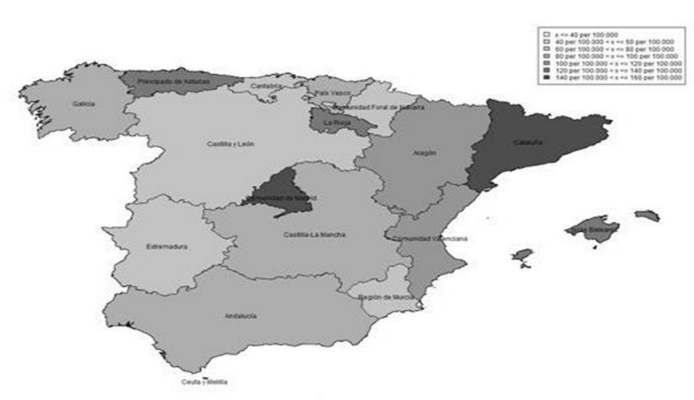

Islias \&anarjas

Figure 2: Regional hospitalization rates due to hepatitis C in Spain (20042014).
During the 11 year study period, a total of 36,235 deaths were reported. The mortality rate was 7.31 deaths per 100,000 (CI 95\%: 7.24$7.39)$, being significantly higher $(\mathrm{p}<0.001)$ in men with 9.11 deaths per 100,000 (CI 95\% 8.99-9.23) than in women with 5.56 deaths per 100,000 (CI 95\% 5.47-5.65). The mortality rate increased significantly with age $(\mathrm{p}<0.001)$, reaching the highest value in those aged 80-84 with 35.53 deaths per 100,000 population (CI 95\%: 34.51-36.54). The case-fatality rate was $6,70 \%$ (CI 95\%: 6.63-6.77), increasing significantly $(\mathrm{p}<0.001)$ with age and being significantly higher in females than in males with 7.02\% (CI 95\%: 6.91-7.13) and 6.51\% (CI 95\%: $6.43-6.60 ; p<0.001)$, respectively. Both mortality rate and case-fatality rate were stable during the study period.

Most frequent complications and comorbidities are shown in table 2. All comorbidities or complications more prevalent than 1 per 1,000 hospitalized patients were included in the table, being HIV, type II diabetes, thrombocytopenia, acquired hypothyroidism, hepatitis B and obesity the most frequent. Case-fatality rate was found to be significantly higher $(\mathrm{p}<0.001)$ for type II diabetes, encephalitis, myelitis and encephalomyelitis and thrombocytopenia, meanwhile it was significantly lower for proteinurias when compared to all the hepatitis $\mathrm{C}$ related hospitalizations. The average length of hospital stay for patients with paraproteinemia, chronic glomerulonephritis, complications of transplanted kidney, Sjögren-Gougerot, inflammatory neuropathies, encephalitis, myelitis and encephalomyelitis and nephritis and nephropathy with lesion of membranous glomerulonephritis was significantly higher than for all the hepatitis $\mathrm{C}$ related hospitalizations. For almost all comorbidities, the readmission rate was also significantly higher when compared to all the hospitalizations. Patients with HIV or hepatitis B infection apart from the hepatitis $\mathrm{C}$ infection were significantly younger than the rest of hospitalized patients with hepatitis $\mathrm{C}$, meanwhile patients with type II diabetes or rheumatoid arthritis were significantly older. One half $(n=17,639$ : $49 \%$ ) of the 36,235 deaths reported in the study period, occurred in patients presenting at least one of the selected comorbidities shown in table 2.

\begin{tabular}{|c|c|c|c|c|c|c|}
\hline Comorbidity & $\mathbf{N}$ & Number of deaths & $\begin{array}{c}\text { Case-fatality } \\
\text { rate/\% }\end{array}$ & Readmissions/\% & Mean age/ Years (SD) & $\begin{array}{c}\text { Average Length of } \\
\text { Stay/ days (SD) }\end{array}$ \\
\hline Type II diabetes & 73,517 & 5,872 & 7.99 & 19.3 & $67.68(12.83)$ & $9.29(11.86)$ \\
\hline Type I diabetes & 1,463 & 95 & 6.49 & 18.5 & $53.91(14.96)$ & $9.62(11.80)$ \\
\hline Obesity & 12,706 & 717 & 5.64 & 15 & $60.58(14.75)$ & $8.89(11.21)$ \\
\hline Paraproteinemia & 3,984 & 259 & 6.5 & 23.3 & $60.75(14.14)$ & $12.95(16.51)$ \\
\hline Acquired hypothyroidism & 15,971 & 1,021 & 6.39 & 16.5 & $66.26(15.02)$ & $9.54(12.12)$ \\
\hline Chronic glomerulonephritis & 638 & 32 & 5.02 & 23.8 & $53.18(12.01)$ & $10.70(12.52)$ \\
\hline Complications of transplanted kidney & 3,439 & 162 & 4.71 & 22.5 & $52.22(12.49)$ & $12.67(16.19)$ \\
\hline Proteinuria & 498 & 6 & 1.2 & 13.3 & $54.23(14.33)$ & $8.95(10.03)$ \\
\hline Psoriasis & 5,381 & 286 & 5.31 & 16.8 & $55.19(15.05)$ & $9.90(12.55)$ \\
\hline Sjögren-Gougerot & 1,078 & 54 & 5.01 & 17.7 & $69.98(11.26)$ & $10.22(11.63)$ \\
\hline Inflammatory neuropathies & 4,513 & 309 & 6.85 & 20.6 & $64.82(13.99)$ & $10.18(11.61)$ \\
\hline Encephalitis, myelitis and encephalomyelitits & 445 & 65 & 14.61 & 20.4 & $54.17(15.55)$ & $18.14(20.76)$ \\
\hline Thrombocytopenia & 18.046 & 1.703 & 9.44 & 17.7 & $58.85(16.00)$ & $10.04(12.92)$ \\
\hline Rheumatoid arthritis & 2,133 & 143 & 6.7 & 14.6 & $67.38(12.92)$ & $9.76(11.12)$ \\
\hline HIV & 85,278 & 5,634 & 6.61 & 19.2 & $43.04(6.92)$ & $10.89(14.13)$ \\
\hline Hepatitis B & 15,887 & 1,154 & 7.26 & 17.6 & $50.98(14.66)$ & $10.27(15.94)$ \\
\hline glomerulonephritis & 587 & 27 & 4.6 & 21.1 & $54.68(13.15)$ & $11.86(13.59)$ \\
\hline Disorders of porphyrinmetabolism & 1,617 & 100 & 6.18 & 16.1 & $59.68(13.00)$ & $8.97(10.13)$ \\
\hline Nephritis and nem & \\
\hline
\end{tabular}

Table 2: Most frequent comorbidities present in patients hospitalized with hepatitis C in Spain (2004-2014). 


\section{Discussion}

The objective of this epidemiologic study was to show the hospitalization burden of severe hepatitis $\mathrm{C}$ in Spain and to highlight its impact on public health. This is to the date the first study reporting national population data on hospitalizations related to hepatitis $\mathrm{C}$ in Spain. Our results show more than half a million hospitalizations in eleven years with a hospitalization rate of 109 cases per 100,000 in general population and reaching almost 200 per 100,000 in $40-49$ years-old adults and 280 per 100,000 in the elderly.

Consistently with previously published data in France, our data show that the hospitalization and mortality rate were significantly higher in males, which was expected due to the higher number of infections among men, and increased significantly with age [21]. Number of hospitalizations and hospitalization rates increased in the last years according to USA data from Nationwide Inpatient Sample $[17,22]$ and Los Angeles County [23]. Another study performed in the USA evaluating national trends from 1996 to 2010 in hospitalizations for patients with HIV and HCV infection or coinfection in primary diagnostic position showed that hospitalizations in HCV monoinfected patients were declining less than in those with only HIV or both $\mathrm{HIV} / \mathrm{HCV}$ infections, and concluded that more resources were needed for HCV monoinfection [15]. In Spain, on the contrary, hospitalization rates shown in table 1 significantly decreased during the studied period. These figures could seem different to published data $[15,17,22,23]$, but can in fact not directly be compared due to the different periods evaluated. In our study, hospitalization rates slightly decreased until 2010, sharply decreased in 2011, and slightly increased again since 2011 .

Case-fatality rate in our study was $6.7 \%$ and was in line with previously published studies $[15,22]$. It increased with age and with the presence of comorbidities, being of great interest the increase in the risk of death in non-hepatic comorbidities also found in other studies $[15,17,24]$. We did not find a sharp increase in the case-fatality rate for HIV and/or hepatitis B coinfection with hepatitis C in our study. But we found that these patients were significantly younger than all hepatitis $\mathrm{C}$ patients. The fact of being younger on average could have masked the comorbidity effect and explain the peak in hospitalization rates found for young adults. On the contrary to hospitalization rates, no significant variations were observed neither in mortality rate nor in case-fatality rate between 2004 and 2014 in our study.

The Spanish Ministry of Health designed in May 2015 a strategic plan to address the problem of hepatitis $\mathrm{C}$ infection in the National Health System including the use of new direct-acting antiviral drugs for the treatment of chronic hepatitis $\mathrm{C}$ infection that have been approved in several countries including Spain. They are more effective and better tolerated than previous treatments, decreasing substantially the side effects, the development of severe complications, and increasing compliance and curing rates [25]. Future studies updating the information presented in this study will be essential to evaluate the results.

This study has some limitations inherent to the use of secondary population data bases. The CMBD only records hospitalized cases; therefore, our results cannot be taken as incidence or prevalence rates. The reliability of the CMBD depends on the quality of the discharge report and the clinical history, as well as the codification process variables. The validity of CMBD and the codification process have been evaluated and it is considered as a useful tool for this analytic approach [26]. Our study aimed to assess the hospitalization burden of hepatitis $\mathrm{C}$ infection, therefore we included hospitalizations with an ICD 9CM code of hepatitis $\mathrm{C}$ not only in first diagnostic position, but in secondary positions. It is well established that patients with chronic $\mathrm{HCV}$ infection have higher all-cause hospitalization rate than other health system patients [27].

Studies reporting the burden of hepatitis $\mathrm{C}$ related hospitalizations and their associated comorbidities are useful for the evaluation of real world needs in treatment and preventive measures and can give interesting information on high risk groups towards which these measures might be directed. In the absence of very effective preventive measures against hepatitis $C$, such as a vaccine, the use of effective treatments in earlier stages of the disease could reduce the huge hospitalization burden of this disease and avoid important complications. New treatments available in Spain since 2015 are a promising hope for the reduction of the hospitalization burden and the associated deaths in hepatitis $\mathrm{C}$ infected patients.

\section{Acknowledgments}

Thanks to the Subdirección General delInstituto de Información Sanitaria for providing the information upon which this study is based.

\section{Funding}

The cathedra "Evaluación de Result adosen Salud, Rey Juan Carlos University" is sponsored by Abbvie.

\section{References}

1. Petruzziello A, Marigliano S, Loquercio G, Cozzolino A, Cacciapuoti C (2016) Global epidemiology of hepatitis C virus infection: An up-date of the distribution and circulation of hepatitis $\mathrm{C}$ virus genotypes. World $\mathrm{J}$ Gastroenterol 22: 7824-7840.

2. Bruguera M, Forns X (2006) [Hepatitis C in Spain]. Med Clin (Barc) 127: 113-117.

3. Bruggmann P, Berg T, Øvrehus AL, Moreno C, Brandão Mello CE, et al. (2014) Historical epidemiology of hepatitis $\mathrm{C}$ virus (HCV) in selected countries. J Viral Hepat 1: 5-33.

4. Hajarizadeh B, Grebely J, Dore GJ (2013) Epidemiology and natural history of HCV infection. Nat Rev Gastroenterol Hepatol 10: 553-562.

5. Westbrook RH, Dusheiko G (2014) Natural history of hepatitis C. J Hepatol 61: 58-68.

6. Norton BL, Park L, McGrath LJ, Proeschold Bell RJ, Muir AJ, et al. (2012) Health care utilization in HIV-infected patients: assessing the burden of hepatitis $\mathrm{C}$ virus coinfection. AIDS Patient Care STDS 26: 541-545.

7. Global Burden of Disease Liver Cancer Collaboration, Akinyemiju T, Abera S, Ahmed M, Alam N, et al. (2017) The Burden of Primary Liver Cancer and Underlying Etiologies From 1990 to 2015 at the Global, Regional, and National Level: Results From the Global Burden of Disease Study 2015. JAMA Oncol.

8. Cacoub P, Gragnani L, Comarmond C, Zignego AL (2014) Extrahepatic manifestations of chronic hepatitis $C$ virus infection. Dig Liver Dis 46 : 165-173.

9. Galossi A, Guarisco R, Bellis L, Puoti C (2007) Extrahepatic manifestations of chronic HCV infection J Gastrointestin Liver Dis 16 : 65-73.

10. Zignego AL, Craxì A (2008) Extrahepatic manifestations of hepatitis C virus infection. Clin Liver Dis 12: 611-636. 
11. Lawitz E, Sulkowski MS, Ghalib R, Rodriguez-Torres M, Younossi ZM, et al. (2014) Simeprevir plus sofosbuvir, with or without ribavirin, to treat chronic infection with hepatitis $\mathrm{C}$ virus genotype 1 in non-responders to pegylated interferon and ribavirin and treatment-naive patients: the COSMOS randomised study. Lancet 384: 1756-1765.

12. US Food and Drug Administration (2014) FDA approves Viekira Pak to treat hepatitis C. FDA News Release, US Food and Drug Administration, USA.

13. US Food and Drug Administration (2016) FDA approves Epclusa for treatment of chronic Hepatitis C virus infection. US Food and Drug Administration,USA.

14. Myers RP, Liu M, Shaheen AA (2008) The burden of hepatitis C virus infection is growing: a Canadian population-based study of hospitalizations from 1994 to 2004. Can J Gastroenterol 22: 381-387.

15. Oramasionwu CU, Toliver JC, Johnson TL, Moore HN, Frei CR (2014) National trends in hospitalization and mortality rates for patients with HIV, $\mathrm{HCV}$, or HIV/HCV coinfection from 1996-2010 in the United States: cross-sectional study. BMC Infect Dis 14: 536.

16. Xu F, Tong X, Leidner AJ (2014) Hospitalizations and costs associated with hepatitis $\mathrm{C}$ and advanced liver disease continue to increase. Health Aff (Millwood) 33: 1728-1735.

17. Tong X, Spradling PR (2015) Increase in nonhepatic diagnoses among persons with hepatitis C hospitalized for any cause, United States, 2004-2011. J Viral Hepat 22: 906-913.

18. Ministerio de Sanidad y Consumo (1994) Clasificación internacional de enfermedades 9 revisión, Modificación clínica, Ministerio de Sanidad y Consumo, Spain.
19. Instituto Nacional de la Salud (2002) Conjunto Mínimo Básico de Datos. Hospitales del INSALUD2001. Instituto Nacional De La Salud, Subdirección General de Coordinación Administrativa, Madrid, Spain.

20. Cuadrado AR, García MDMS, Ruiz RC, Torre MPDL (1999) Análisis y desarrollo de los GDR en el Sistema Nacional de Salud. Ministerio De Sanidad Y Consumo, Spain.

21. Rotily M, Abergel A, Branchoux S, De LL, Vainchtock A, et al. (2014) Burden Of Hospitalizations Related To Chronic Hepatitis C In France: Evolution Between 2009 And 2012. Value Health 17: 364

22. Luo R, Greenberg A, Stone CD (2015) Increasing Volume but Decreasing Mortality of Hospitalized Hepatitis C Patients in the United States, 2005 to 2011. J Clin Gastroenterol 49: 620-627.

23. Sie L, Gatto NM, Bancroft E (2013) Hospitalizations due to hepatitis C in Los Angeles County, 2007-2009: case characteristics and factors associated with mortality. J Viral Hepat 20: 628-637.

24. Golabi P, Otgonsuren M, Suen W, Koenig AB, Noor B, et al. (2016) Predictors of Inpatient Mortality and Resource Utilization for the Elderly Patients With Chronic Hepatitis C $(\mathrm{CH}-\mathrm{C})$ in the United States. Medicine (Baltimore) 95: 2482.

25. Ministerio de Sanidad, Servicios Sociales e Igualdad (2015) Plan estratégico para el abordaje de la hepatitis C en el Sistema Nacional de Salud. Ministerio de Sanidad, Servicios Sociales e Igualdad, Spain.

26. Peiro S, Librero J (1999) Evaluación de la calidad a partir del conjunto mínimo de datos básicos al alta hospitalaria. Rev Neurol 29: 651-661.

27. Teshale EH, Xing J, Moorman A, Holmberg SD, Spradling PR, et al (2016) Higher all-cause hospitalization among patients with chronic hepatitis C: the Chronic Hepatitis Cohort Study (CHeCS), 2006-2013. J Viral Hepat 23: 748-754. 